\title{
COMPARATIVE ANALYSIS ON THE EFFECT OF HEAVY METALS: A CASE STUDY OF SELECTED STATES IN NIGERIA
}

\author{
Isa, ${ }^{1,2}$ N. F. Gana ${ }^{2}$ U. M. Ibrahim ${ }^{1,2} U$. M.* ${ }^{*}$ Ahmed, ${ }^{1,2}$ F. Said, ${ }^{3}$ M. Salihu, ${ }^{4}$ I. M. Haladu, ${ }^{5} B$. \\ Bello ${ }^{6} \mathrm{~A}$. Bala, ${ }^{7}$ S. and Ibrahim, ${ }^{8}$ A. M. \\ ${ }^{1}$ Centre for Renewable Energy Research, ${ }^{2}$ Department of Physics, Bayero University, Kano \\ ${ }^{3}$ Department of Physics Yusuf Maitama Sule University, Kano; ${ }^{4}$ Department of Biology, Federal \\ Polytechnic Bida, Niger State; ${ }^{5}$ Department of Physical Science, Rabiu Musa Kwankwaso, College of \\ Advanced and Remedial Studies T/Wada Kano State Nigeria; ${ }^{6}$ National Research Institute for \\ Chemical Technology, Basawa Zaria, Kaduna State, Nigeria, ${ }^{7}$ Department of Mathematical sciences \\ Bayero University, Kano. ${ }^{8}$ Gidan Kwanu Primary and Secondary School, Minna Niger state. \\ Corresponding author: umibrahim.phy@buk.edu.ng, (+234)8037375353
}

\section{ABSTRACT}

In the toxicological aspect, uncontrolled amount of heavy metals is deadly, to the environment and its inhabitants. To complicate issues, reviewed work has revealed that technological advancement is one of the key sources of heavy metals. This can lead to outbreak of diseases, decrease of life span, cancer, and other related effects. Providing sustainable environment, the concentration of these metals need to be periodically regulated. This research studies the effect of some selected heavy metals (Fe, Cd, Cu, Ni, $\mathrm{Cr}, \mathrm{Pb}, \mathrm{Zn}$ and $\mathrm{Mn}$ ) in Kano State Nigeria, using Atomic Absorption spectroscopy (AAS). The results were compared with other related work conducted in some states across Nigeria (Akwa Ibom, Kwara, Kaduna, and Bauchi States) and standard international values (WHO, FAO, SEPA and US EPA). The parameters analysed were; Concentration, Bioaccumulation (Plant concentration factor -PCF), Transfer factor (TF), Daily Intake of Metals (DIM), and Health Risk Index (HRI). Statistical package (SPSS) was used, to establish the relationship between these metals in all the sites. The result showed that there were substantial absorption of these metals by the plants and the consumers. Children were more exposed than adults in terms of DIM and the HRI. The comparison showed sequential order in the parameters investigated. All the biological samples exhibited Phytoremediation quality with the $T F>1$, this will aid in having sustainable environment to the resident and citizen of the state in particular and the nation in general, as well as serving as an impetus for the initiation of safe comprehensive remedy of the subject matter. The PCF for all the samples varied across states and plants.

Keywords: AAS, Adults, ANOVA. Children, Concentration, DIM, HRI, PCF, Phytoremediation,

\section{INTRODUCTION}

Heavy metal has been widely reported to record variable health effect. Among the major contributors of heavy metals to the environment is technological advancement, and if not properly checked their presence can lead to outbreak of disease, short life span, cancer and other related effects (Isa et al. 2018 \& Khan et al. 2008).

Effort have been made by researchers across the globe in studying heavy metals and their sources. In 2006, Trang lead his team to study dust in the metropolitan city of Korea. They reported variable concentrations in $\mathrm{Cd}, \mathrm{Zn}, \mathrm{Ni}$, $\mathrm{Cu}$ and $\mathrm{Pb}$, in the sequence $\mathrm{Cd}>\mathrm{Ni}>\mathrm{Zn}=\mathrm{Pb}>\mathrm{Cu}$, using Atomic Absorption Spectroscopy (AAS). The transmission of this heavy metals and their health effect were studied in Beijing, considering the irrigation system (long-term waste water). The results was compared with WHO, and SEPA. The finding shows relative absences of health risk (Khan et al.). Naser et al., (2011) studied the level of heavy metals in vegetables and found the metals in the sequence: $\mathrm{Cd}>\mathrm{Co}>\mathrm{Pb}>\mathrm{Ni}>\mathrm{Cr}$. The results were further analysed using statistical soft wares. The study equally used AAS and compared its result with WHO. In Nigeria Mbong lead his team to study citrus in urban and rural area of Oyo. The soil plant heavy metals were equally studied and employ AAS in their analysis (Mbong et al, 2014).In the same year in zaria, Zakka studied heavy metals uptake by plants in metals dump sites. They studied different plants species using AAS (Zakkaet al 2014). Years later the concentrations of heavy metals were study along road side in kwara state and variable results were reported. In the same line in Bauchi $\mathrm{Pb}-\mathrm{Zn}$ were equally studied in mining area (Ogundele et al, 2015 \& Sanusi et al 2017). 
This paper studied five selected LGA in Kano state Nigeria (as shown in Plate 1). Soil concentrations, Bioaccumulation, Transfer factors, Daily intake of metals and Hazard index are the parameters determined. These results were then compared with some selected states in Nigeria, Other international countries and standard organization values. Statistical Analysis of the data was carried out using SPSS 20.0 software package.

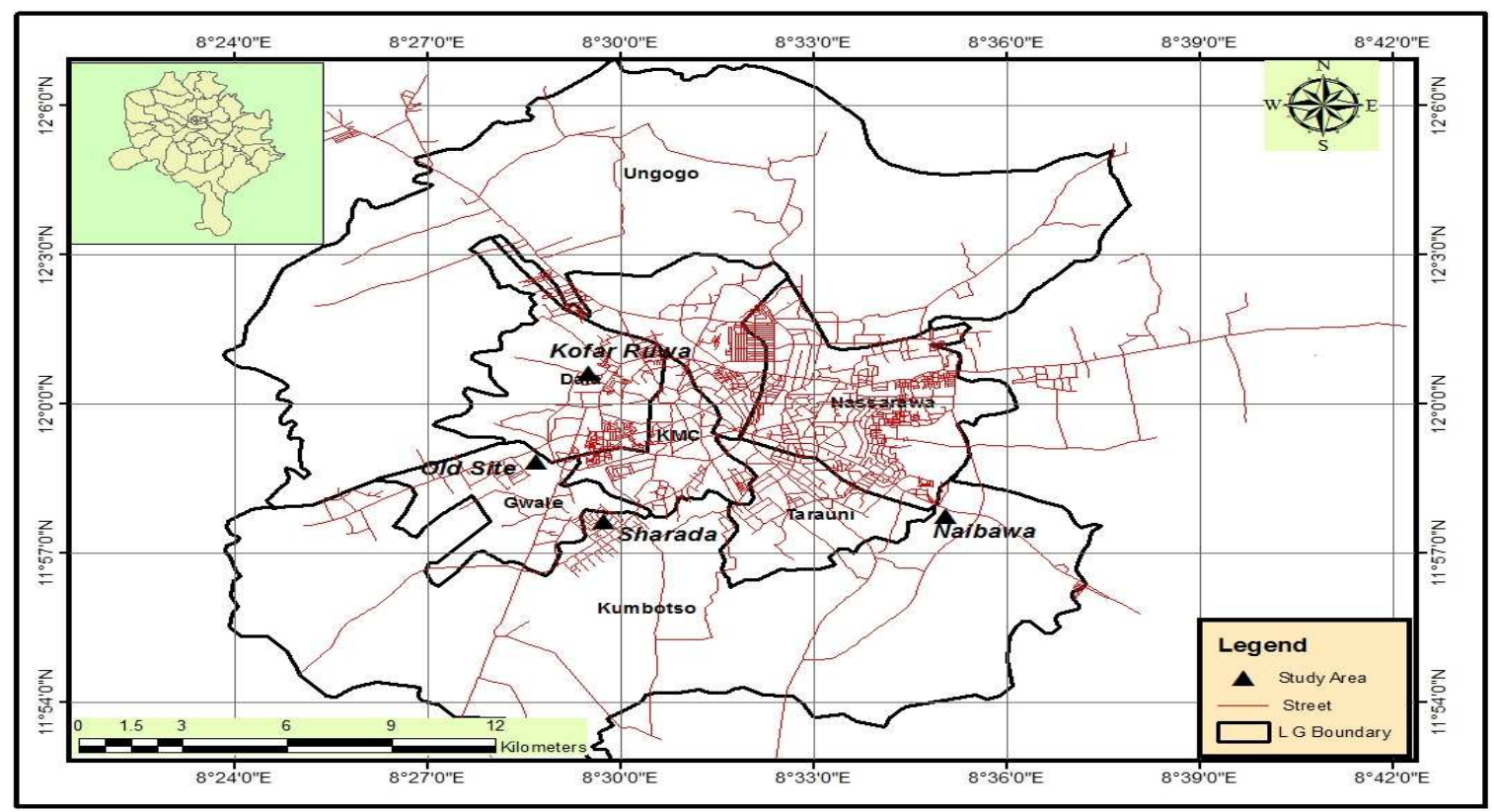

Plate 1: The five selected local Government Areas in Kano State Nigeria (Gwale - two sites, Kumbotso, Sharada and Dala LGA)

Computation of concentrations.

The concentration of heavy metals is directly related to the absorbance of metals by samples. In order to have the concentrations of these metals one needs to use some formulae. The research is aimed at, studying biological and soil samples with parameters: concentration ( $\mathrm{C}$ sample), the plant concentration factor (PCF) and Pollution Load Index (PLI). The formulae are given by (Udo et al., 2009 and Khan et al., 2008):

\section{Concentration of sample ( $\left.C_{\text {sample }}\right)$}

$$
C_{\text {sample }}=\left(\frac{\text { Abs. }}{\text { Standard/Slope }}\right) \times \frac{\text { Volume }}{\text { Weight of Sample }}
$$

where Abs. is Reading of absorbance of Heavy Metals.

\section{Plant Concentration Factor (PCF)}

III. Pollution Load Index (PLI)

$$
P C F=\frac{C_{\text {Plant Sample }}}{C_{\text {Soil Sample }}}
$$

\section{Standard/Slope}

$$
P L I=\frac{C_{\text {Soil Sample }}}{C_{\text {Plant Sample }}}
$$

The standard (Slope) value was obtained using equation 4 . The equation was given as:

$$
C_{1} V_{1}=C_{2} V_{2}
$$

where $\mathrm{C}$ is the concentration of solution and $\mathrm{V}$ is the volume.

Daily Intake of Metals (DIM)

Calculation of oral intake of metals from soil through consumable plants/vegetable was computed using equation (5) given as (Cui et al., 2004): 


$$
\begin{aligned}
& \text { DIM } \\
& =M_{\text {sample }} \\
& \times C_{\text {metal }}
\end{aligned}
$$

where DIM is Daily Intake of Metals $(\mathrm{mg} / \mathrm{kg}$ ), $M_{\text {sample }}$ is Mass of consumable plants/vegetable $(\mathrm{kg})$ and $\mathrm{C}_{\text {metal }}$ is the Concentration of Heavy Metals in the sample $\left(\mathrm{mgkg}^{-1} \mathrm{day}^{-1}\right)$.

Daily Intake Rate (DIR)

Arora et al., (2008) and Sajjad et al., (2009) led their teams and presented that daily intake rate is the product of the average metal content in each vegetable (plants) with the respectable consumable rate. The mathematical representation is given as:

$$
\begin{aligned}
& \text { DIR } \\
& =C_{\text {metal conc. }} \times C_{\text {factor }} \\
& \times \text { DIM }
\end{aligned}
$$

where $\mathrm{C}$ metal conc. is the heavy metals concentration $(\mathrm{mg} / \mathrm{kg}), C_{\text {factor }}$ is the conversion factor (can be calculated using equation 7 as IRdw) and DIM is the daily intake of metals (kg day $^{-1} \mathrm{FW}$ ).

The conversion factor is set to convert fresh vegetable sample weight to dry weight based on equation (7) given as:

$$
\begin{aligned}
& I R d w \\
& =I R w w\left[\frac{100-W}{100}\right]
\end{aligned}
$$

where IRdw is dry-weight intake rate (Conversion factor), IRww is the wet intake rate and $\mathrm{W}$ is percentage of water content. The conversion factor used was 0.085 .

\section{Hazard Quotient (HQ)}

United State Environmental Protection Agency (USEPA 2000) characterized human health risk using $\mathrm{HQ}$ defined it as the ratio of exposure to the product of Body weight and referral oral dose $\left(R_{f} D\right)$. It is mathematically represented in equation 8 as:

$$
=\frac{D I M \times C_{m}}{R_{f} D \times B W}
$$

where DIM is Daily Intake of Metals ( $\mathrm{kg} /$ day), $C_{m}$ Concentration of Metals $(\mathrm{mg} / \mathrm{kg})$ and $R_{f} D$ is the Oral referral dose for metals $(\mathrm{mg} / \mathrm{kg}$ of body weight).

\section{RESULTS AND DISCUSSION}

Equations 1 to 8 were used to compute related values in line with the parameters this paper aimed at. The values obtained were subjected to simple graphical representation (presented in Figure 1 to 4 ) and statistical analysis software package- SPSS 20.0 (presented in Figures 5 to 12). The figures were in respect to the five locations in Kano state and other related works (both national and internationals).

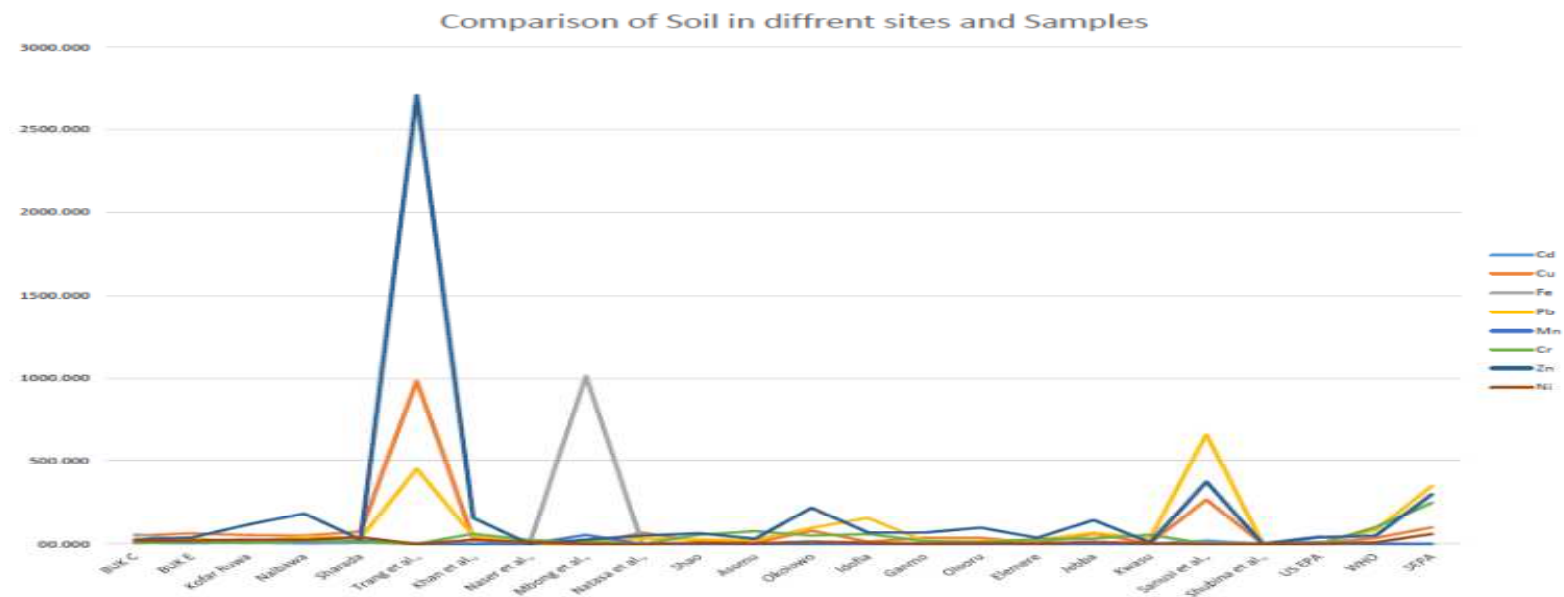

Figure1: Comparison of Soil Concentrations, between this work, other related work within Nigeria, international related work and standard permissible values.

Figure 1, it clearly reveals that the concentration in Trang et al (Korea), Mbong et al (Akwa lbom), and Sanusi et al (Bauchi) recorded the highest values and are above the limit given by WHO and SEPA. This work happens to be in the right track (in correlation with other work) and below the values of WHO and SEPA but greater than values given by USEPA. 


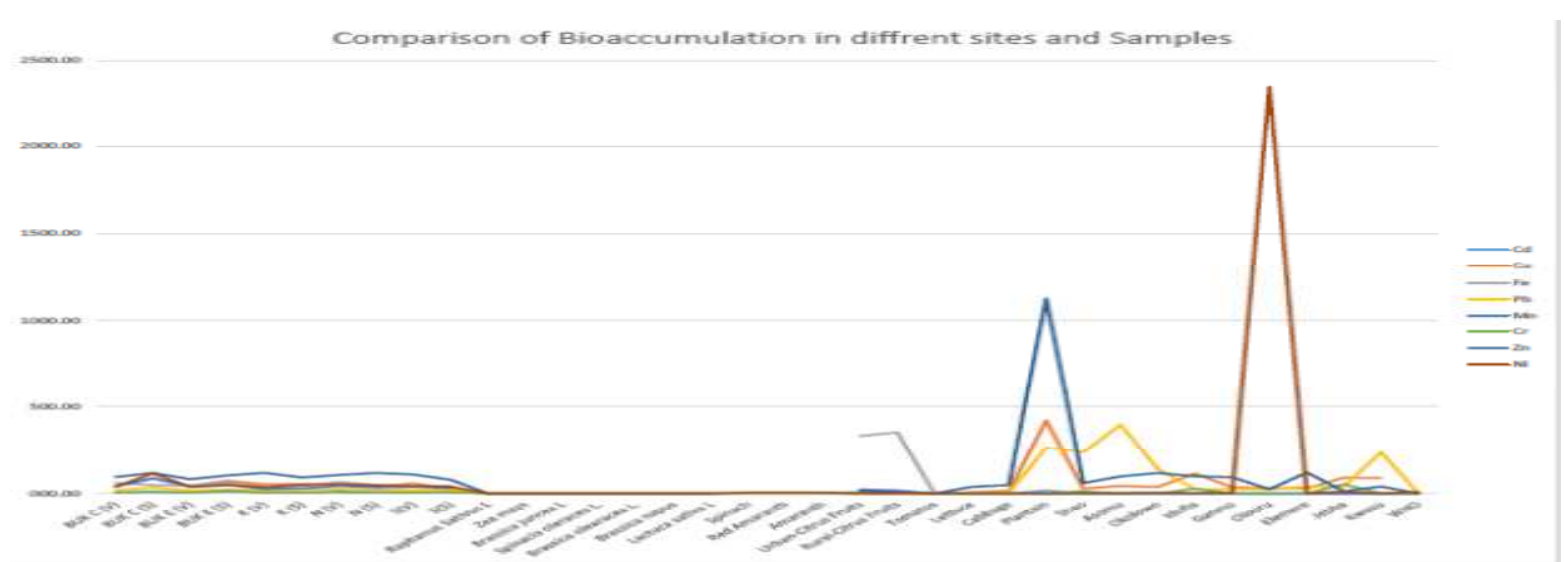

Figure2: Comparison of Bioaccumulation between this work, other related work within Nigeria, international related work and standard permissible values.

Figure 2 shows the comparison of the concentrations present in plants, and this work in the figure is within mid region (as it is not the minimum and not the maximum recorded values) with values less than or equal to WHO permissible values. Biological samples in Kwara (Grasses), India (Cabbage and plantain), recorded the highest values which are all above the permissible limit given by WHO.

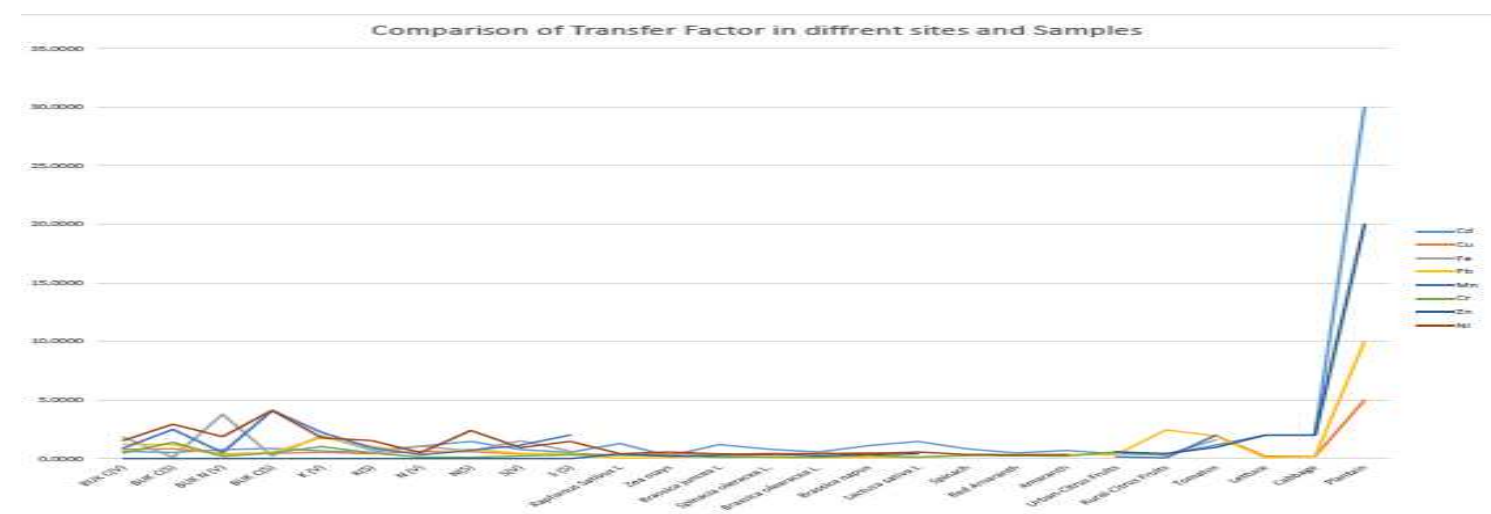

Figure3: Comparison of Transfer factor between this work, other related work within Nigeria, and international related work.

The transfer factor reported in Figure 3 gave almost a uniform distribution of pattern with values greater than 1 . This means that all the plant can be employed for phytoremediation.
Each biological plant has recorded certain value of concentration of Heavy metals. Cabbage and Plantain (Natasa et al) recorded the highest values.

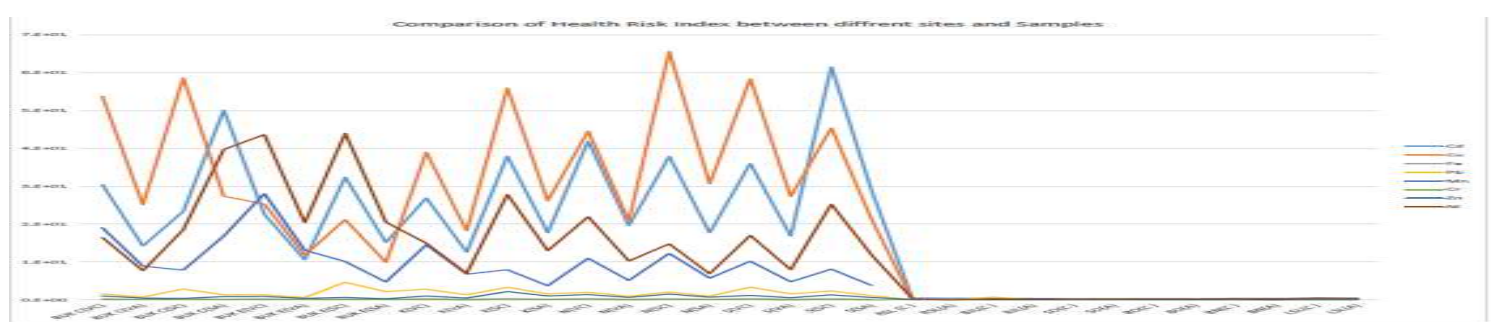

Figure4: Comparison of Health Risk Index between this work and international related work.

Figure 4, obviously shows that the health risk index in children is higher than in adults. This research has recorded very high values than the work of Khan et al (India).
In justifying the comparison, SPSS 20.0 software was used to analyse the data. $P<0.05$ was considered significant. 


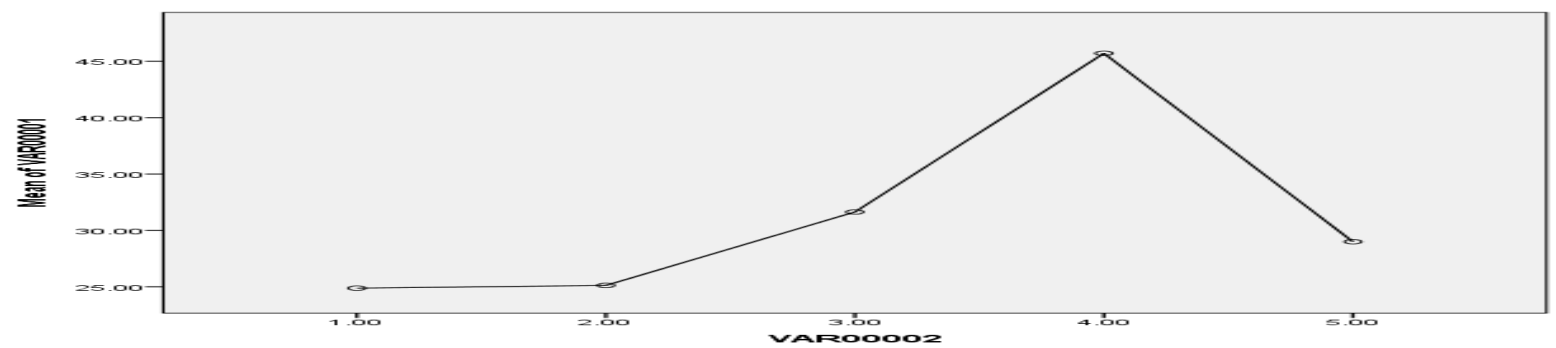

Figure 5: Mean of Variance against the sites (In this work), for soil concentration

The soil concentration in this work shows no significant variations. A Test of Homogeneity of Variances gave a $\mathrm{P}$-value of 0.343 , hence
ANOVA test value of 0.745 was obtained. Figure 5 gave the details of mean variance analysis.

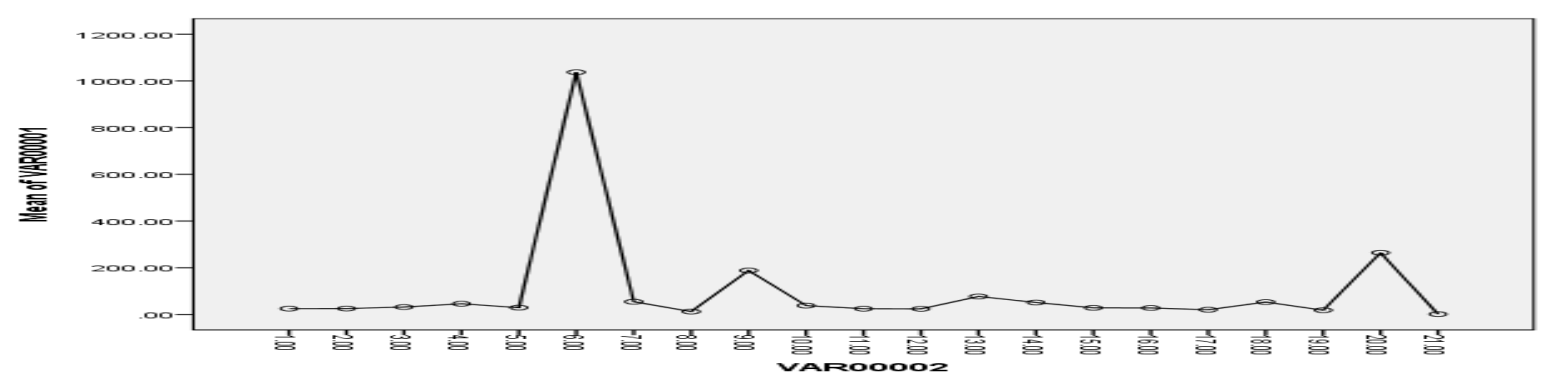

Figure 6: Mean of Variance against the sites (In all sites), for soil concentration

The result obtained in this work was compared with other works, and a significant difference was recorded with the Test of Homogeneity of Variances $(P<0.05)$, hence Robust Tests of
Equality of Means was assumed, and the Pvalue recorded was 0.175 . Figure 6 gave the details of mean variance analysis.

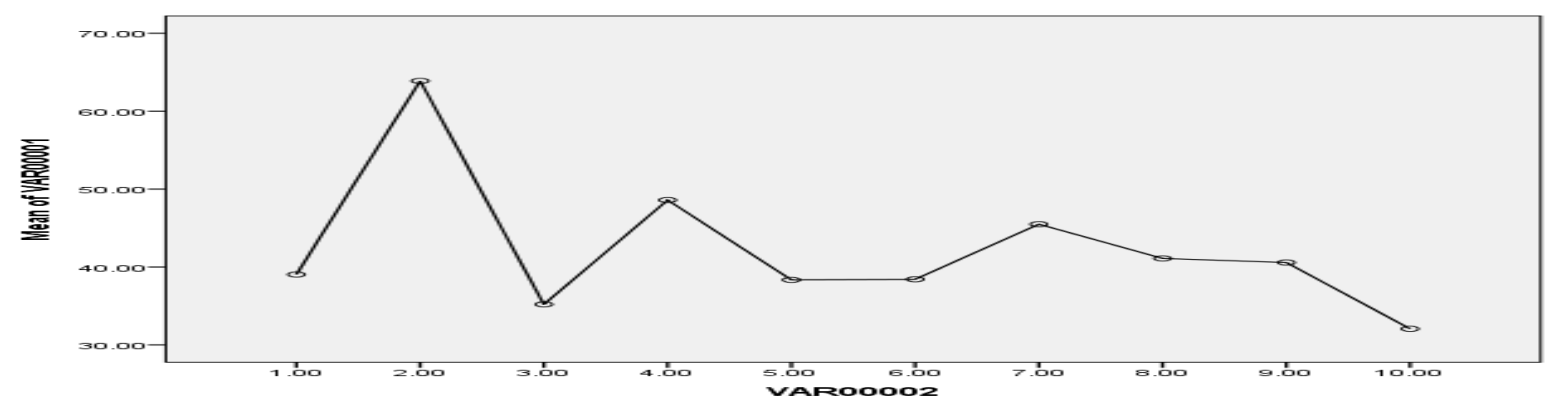

Figure 7: Mean of Variance against the sites (In this work), for bioaccumulation

The bioaccumulation in the five sites does not record significant difference, because 0.696 was the $p$ value for Test of Homogeneity of
Variances $(>0.05)$ and the ANOVA P-value is 0.784 . The plot of Mean variance against the sites is given in figure 7 .

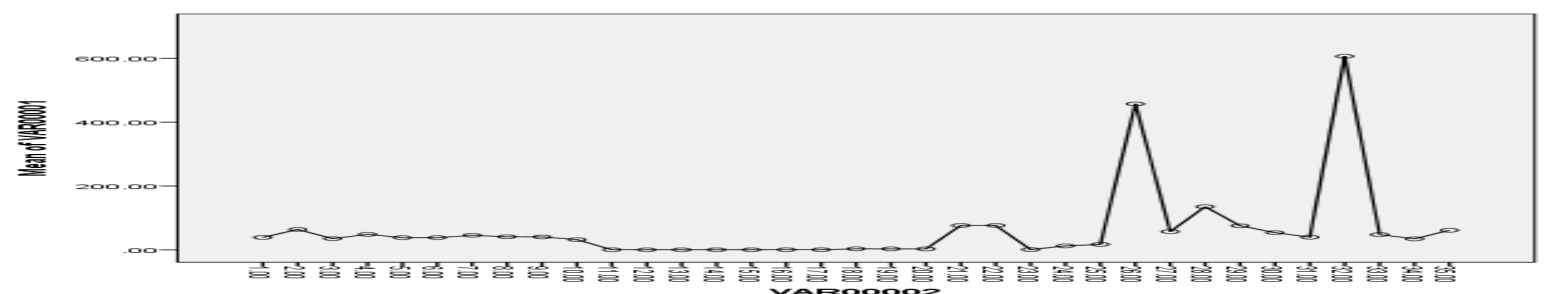

Figure 8: Mean of Variance against the sites (In all sites), for bioaccumulations

In all the sites of interest, the comparison reveals variable values (difference) since the $p$ value is $<0.05$ and the Robust Tests of Equality of Means was assumed with $p$ value of 0.442 . Figure 8 gave more information. 
Test of Homogeneity of Variances for the five sites recorded a P-value of 0.42 , which is greater than 0.05 and ANOVA P-value of 0.848 ,

hence no significant difference recorded. More information can be deduced from figure 9 .

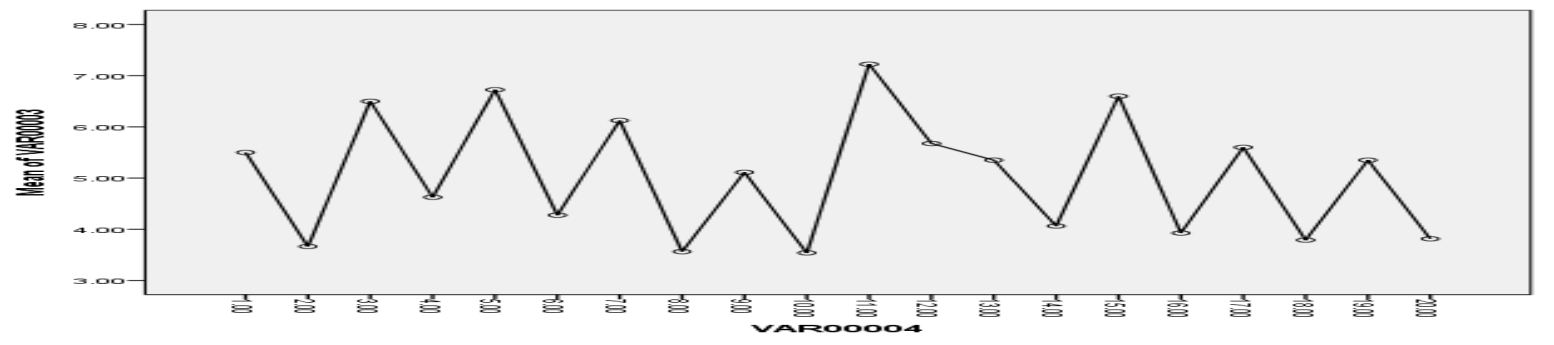

Figure 9: Mean of Variance against the sites (In this work), for DIM

For all the sites considered, DIM recorded significant difference with Test of Homogeneity of Variances and Robust Tests of Equality of
Means $p$ value of $<0.05$. Clearly figure 10 gave the pictorial difference in variance.

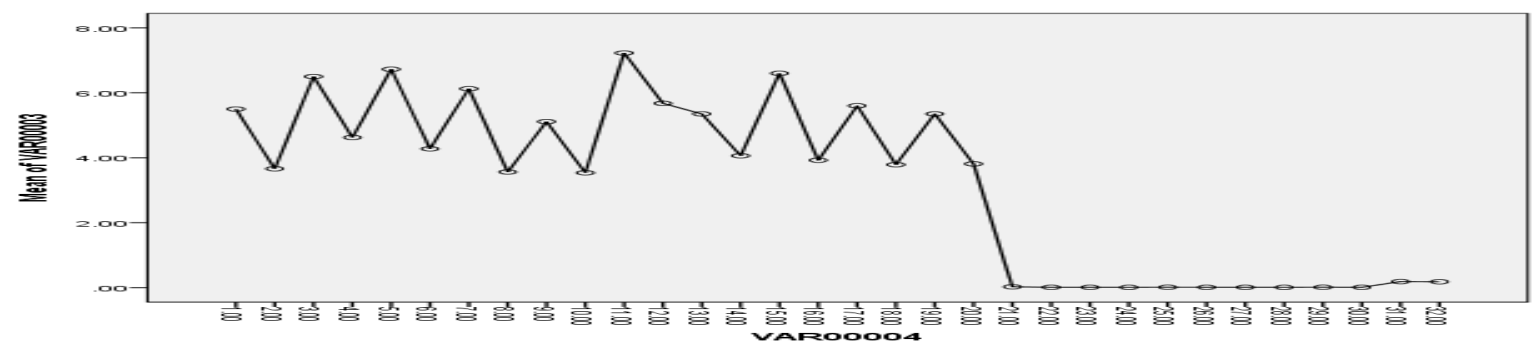

Figure 10: Mean of Variance against the sites (In all sites), for DIM

Similarly the HRI for the five sites have no significant difference with Test of Homogeneity of Variances less than 0.05 and assuming Robust

Tests of Equality of Means of 0.879 . Figure 11 elaborate the more.

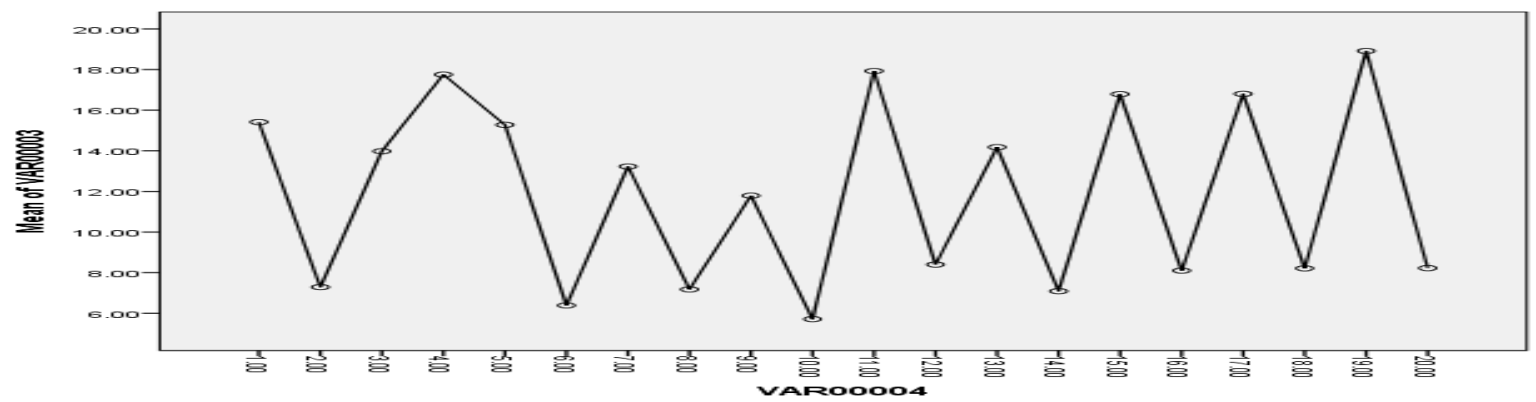

Figure 11: Mean of Variance against the sites (In this work), for HRI

The HRI in all the sites recorded significant Variances and Robust Tests of Equality of Means difference with Test of Homogeneity of are less than 0.05 . Figure 12 give more details.

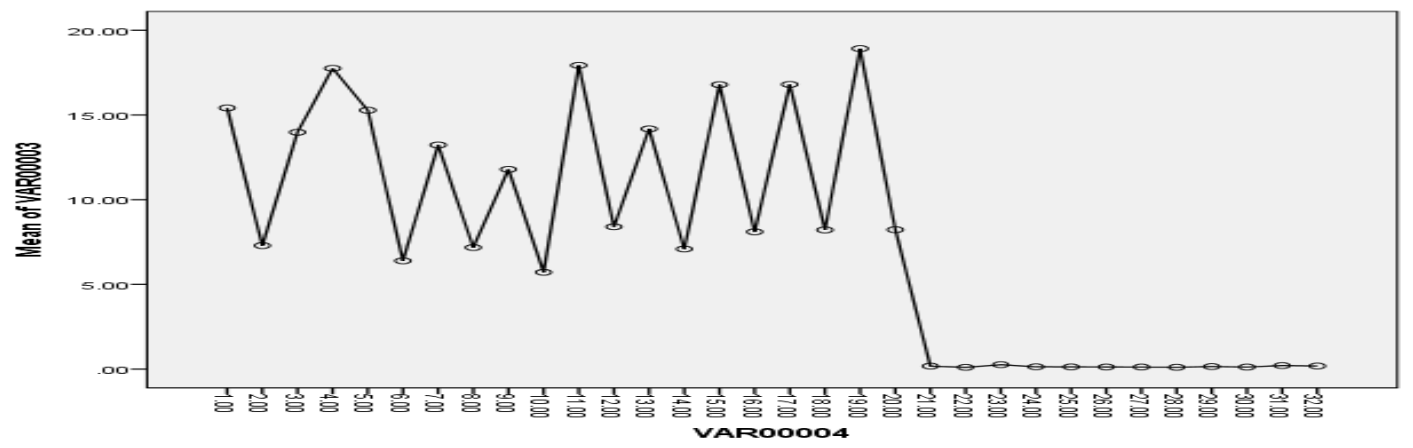

Figure 12: Mean of Variance against the sites (In this work), for HRI 


\section{CONCLUSION}

The variable concentrations of eight heavy metals in this work and other metals in related work were studied. The concentrations in this work reveal no significant difference but recorded variable values (difference) in the related work. For the bioaccumulation, all the selected samples recorded variable concentrations in their respective sites. The transfer factor shows the samples potential to be used for phytoremediation, as all the samples recorded values greater than 1 . The daily intake metals (DIM) shows that child are

\section{REFERENCES}

Arora, M., Kiran, S., Rani, S., Rani, A., kaur, B., and Mittal, N., (2008). Heavy Metal Accumulation in Vegetable irrigated with Water from different Sources. Food Chemistry 111:811- 815.

Cui, Y. Z. Y. G., Zhai, R. H., Chen D. Y., Huang Y. Z., Qui, Y. and Liang, J. Z. (2004). Transfer of Metals from Soil to Vegetables in an Area Near a Smelter in Nanning, China. Environment International. 30: 785 - 791.

Khan S., Cao Q., Zheng Y. M., and Zhu Y. G., (2008) Health Risks of Heavy Metals in Contaminated Soils and Food Crops Irrigated With Waste Water in Beijing, China Environmental Pollution, 152:686-692.

Mbong, E. O., Akpan, E. E., and Osu, S.R. (2014). "Soil-Plant Heavy Metal Relations and Transfer Factor Index Of Habitats Densely Distributed With Citrus Reticulated (tangerine)". Journal of Research IN Environmental Science and Toxicology. 3(4):61-65.

Naser H. B., Sarmin, S., and Mahmud, N., U. (2011) Heavy Metal Levels in Vegetables growth Stage and Plant Species Variations. Bangaladash J. Agril. Res. 36(4):563-574

Natasa, M., Rukie, A., Ljubomir, S., Lidija M., and Zoran, S. I. (2015) "Transfer Factor As Indicator of Heavy Metals Content in Plants" Fresenius Environment Bulletin PSP 24(11c):4212-4219

Ogundele D. T., Adio A. A., and Oludele O. E., (2015) Heavy Metal Concentrations in Plants and Soil along Heavy Taffic Roads in Northern Central Nigeria. Environment \& Analytical Toxicology 5(6):334-338 more exposed to heavy metals than adult, in the same line with the health risk index (HRI) (adults are safer than children).

\section{ACKNOWLEDGEMENTS}

I would like to acknowledge Centre for Renewable Energy Research (CRER) and Department of Physics, Faculty of Physical Sciences, Bayero University, Kano, for their financial support, and Late Engr. Muhammadu Ibrahim Wabi for his advice and guide (May Aljantulfirdaus be his final abode). All the sources used, were duly acknowledged and related papers.

Sanusi K. A., Hassan, M. S., Abbas, M., A., and Kura A. M, (2017) Assessment of Heavy Metals Contamination of Soil and Water around abandoned $\mathrm{Pb}-\mathrm{Zn}$ mines in Yelu, Alkaleri Local Government Area of Bauchi State, Nigeria. International Research Journal of Public and Environment Health 4(5): 72-77

Sajjad, K., Robina, F., Shagufta, S., Mohammad, A., and Maria, S., (2009). Health Risk Assessment of Heavy Metals for population via Consumption of Vegetables. World Appl. Science Journal, 6:1602-1606.

Trang T. T. D, Byeong-Kyu, L., Trang, T.T.D., Ui-ryang, J., Ae-ri, K., and Haengah, K. L., (2006) Heavy Metal Contamination of Road Dust City of Ulsan, Korea IEEE IFOST2006 :213-215

Udo, L. J., Trenchard, O. I., Joseph, A. 0. Anthony O. A., Ivara E., E., (2009) Manual of Soil, Plant and Water Analysis. Published by Sibon Books ltd Lagos, ISBN: 97880127 IA, : 57-77.

US EPA (2000). Risk -Based Concentration Table PA: United State Environment Protection Agency, Washington DC www.epa.gov/home/forms/contactepa

Zakka Y. I., Nasiru, R. Ahmed, Y. A. and Abullahi, M. A. (2015). "Measurement of Radon Concentration in Water Sources around Ririwai Artisanal Tin Mine Kano State, Nigeria" Journal of Natural Sciences Research 5(24):22243186. 